\title{
AVALIAÇÃo QUALITATIVA da ÁGUA DE NASCENTES COM DIFERENTES USOS DO SOLO EM SEU ENTORNO
}

\author{
Lilian Vilela Andrade Pintoํㅜ Talita Nazareth de Roma², Kátia Regina de Carvalho Balieiro ${ }^{3}$
}

(recebido: 19 de agosto de 2010; aceito: 30 de março de 2012)

\begin{abstract}
RESUMO: Alguns fatores são responsabilizados pela degradação da qualidade da água dos mananciais. Neste trabalho, objetivou-se avaliar o impacto de diferentes usos do solo sobre as propriedades físicas, químicas e biológicas da água de cinco nascentes situadas em Inconfidentes/MG. Os resultados revelaram que a nascente parcialmente protegida por vegetação nativa apresentou qualidade superior da água quanto aos parâmetros cor, turbidez, demanda bioquímica de oxigênio $\left(\mathrm{DBO}_{5}\right)$, fosfato total, nitrato, oxigênio dissolvido (OD), coliformes totais e coliformes termotolerantes. As causas dos impactos negativos na qualidade das águas colocando em risco o meio ambiente e a saúde humana foram a falta de práticas agrícolas conservacionistas, favorecendo o assoreamento das nascentes; a ausência de cercas no entorno de algumas nascentes, propiciando contaminação da água pelo acesso de animais; a ausência de esgotamento sanitário nas residências rurais e; o abuso de fertilizantes químicos nas lavouras.
\end{abstract}

Palavras-chave: Índice de qualidade da água, legislação ambiental, poluentes da água.

\section{THE EFFECT OF DIFFERENT SOIL USES ON THE QUALITY OF SPRING WATER}

\begin{abstract}
Several factors are known to be responsible for the degradation of water quality in our Planet's spring sources. The goal of this study was to evaluate the impact of different anthropogenic activities on physico-chemical and biological properties of five spring water located in Inconfidentes, Minas Gerais State, Brazil. Analytical results have demonstrated that water source protected by native vegetation had the highest quality in terms of color, turbidity, biological oxygen demand (BOD5), total phosphate, nitrate, dissolved oxygen (DO), fecal coliforms and thermo-tolerant coliforms. On the other hand, the water quality was negatively impacted by the lack of adequate agricultural practices, such as the use of chemical inputs, the nonexistence of fenced livestock grazing areas and residential sewage system which are considered to be indispensable practices to minimize the environmental impact of anthropogenic activities and to protect human health.
\end{abstract}

Key words: Water quality index, enviroment legislation, water pollution.

\section{INTRODUÇÃO}

Nascente ou olho d’água é o local onde aflora naturalmente, mesmo que de forma intermitente, a água subterrânea. A dimensão mínima da faixa marginal de vegetação nativa a ser preservada nas nascentes é de 50 $\mathrm{m}$ de raio, mesmo que intermitente, segundo o Código Florestal (Lei $\left.{ }^{\circ} 4.771 / 65\right)$ (BRASIL, 1965) em seu artigo $2^{\circ}$ e, a Resolução CONAMA 303/2002, artigo $3^{\circ}$, inciso III (BRASIL, 2002). Entretanto, o que se observa muitas vezes é o desrespeito às áreas de preservação permanente, devendo-se imediatamente prever a sua recuperação.

A proteção dessas áreas foi reafirmada na Lei $n^{\circ}$ 9.433/97 (BRASIL, 1997) que instituiu a Política Nacional de Recursos Hídricos que fundamenta-se no fato de que a água, embora reconhecida como um recurso natural renovável, seja também um recurso de domínio público. A referida lei objetiva assegurar à atual e às futuras gerações a disponibilidade de água em padrões adequados aos respectivos usos, além da prevenção e da defesa contra eventos decorrentes de seu uso inadequado.

Conforme Oliveira-Filho et al. (1994), a devastação das matas ciliares tem contribuído para o assoreamento, o aumento da turbidez das águas, o desequilíbrio do regime das cheias, a erosão das margens de grande número de cursos d'água, além do comprometimento da fauna silvestre. Arcova e Cicco (1997) salientam que nas microbacias de uso agrícola o transporte de sedimentos e a perda de nutrientes são maiores quando comparadas às de uso florestal.

A Resolução n ${ }^{\circ}$ 357/05 do Conselho Nacional de Meio Ambiente - CONAMA (BRASIL, 2005) dispõe sobre os níveis de qualidade das águas naturais do território brasileiro, determinando os parâmetros de classificação.

\footnotetext{
${ }^{1}$ Engenheira Florestal, Professora Doutora em Engenharia Florestal - IFSULDEMINAS - Campus Inconfidentes - 37576-000 - Inconfidentes, MG, Brasil - lilian.vilela@ifs.ifsuldeminas.edu.br

${ }^{2}$ Tecnóloga em Gestão Ambiental - IFSULDEMINAS - Campus Inconfidentes - 37576-000 - Inconfidentes, MG, Brasil -tnroma@gmail.com ${ }^{3}$ Médica Veterinária, Professora Doutora em Ciência Animal - IFSULDEMINAS - Campus Inconfidentes - 37576-000 - Inconfidentes, MG, Brasil katia.balieiro@ifsuldeminas.edu.br
}

Cerne, Lavras, v. 18, n. 3, p. 495-505, jul./set. 2012 
Dentre os vários usos da água, o abastecimento humano é considerado o mais nobre, portanto a água para abastecimento de comunidades, mesmo que fora do perímetro urbano, deve apresentar características sanitárias e toxicológicas adequadas, visando a prevenir danos à saúde e garantir o bem-estar do homem (BRAGA et al., 2002). A água também deve ser isenta de substâncias prejudiciais aos organismos que compõem os elos das cadeias alimentares.

Assim, atenção maior deve estar voltada ao abastecimento hídrico das comunidades no ambiente rural, em função da limitação de acesso destas, à infra-estrutura de abastecimento de água potável. Conforme descreveram Clarke e King (2005), mais de um bilhão de pessoas no planeta ainda não têm acesso fácil a uma fonte confiável de água e 1.700 .000 pessoas morrem anualmente em virtude de doenças transmissíveis por ela, sendo as principais a cólera, o tifo e diarréias microbianas diversas.

A água adequada ao abastecimento público deve atender a padrões de qualidade definidos por legislação própria de cada país. No Brasil, o padrão de potabilidade está descrito na Portaria 518/2004 do Ministério da Saúde (BRASIL, 2004), o qual inclui, dentre outros quesitos: a ausência de contaminação por agentes patogênicos, ausência de substâncias tóxicas ou venenosas; além de impor limites quanto à presença de matéria orgânica em solução, dentre outras exigências.

Segundo Barroso e Silva (1992), a degradação da água das nascentes pode ter causas naturais (chuvas, erupções vulcânicas) ou antrópicas. A degradação da qualidade dos recursos hídricos vem ocorrendo intensamente e tem diversas causas como: áreas de recarga ocupadas por atividades agropecuárias sob manejo inadequado; práticas inadequadas de uso da terra, ocasionando erosão dos solos; eliminação da vegetação nativa nas áreas de preservação permanente (APPs) e substituição por culturas agrícolas, por pastagens ou por construção de casas, com consequente despejo de efluentes domésticos (DAVIDE et al., 2004; PINTO, 2003) ou disposição indevida de resíduos sólidos ou domiciliares nas proximidades ou diretamente nos cursos d'água.

Neste trabalho, objetivou-se a caracterização física do entorno de cinco nascentes visando a avaliar os impactos do uso e ocupação do solo nos indicadores de qualidade da água.

\section{MATERIAL E MÉTODOS}

Foram estudadas cinco nascentes no Município de Inconfidentes, MG, situadas no Bairro dos Romas, localizado na bacia hidrográfica do rio Mogi Guaçu, tendo como referência a latitude $22^{\circ} 18^{\prime} \mathrm{S}$ e longitude $46^{\circ} 19^{\prime}$ $\mathrm{W}$, altitude média de $855 \mathrm{~m}$ e $1500 \mathrm{~mm}$ de pluviosidade média anual.

As nascentes avaliadas foram classificadas conforme o uso e a ocupação do solo no seu entorno em: i) Nascente Perturbada, presença de vegetação ciliar em área menor à prevista na Lei n 4.771/65 (BRASIL, 1965); ii) Nascente com pastagem; iii) Nascente com cultivo de café; iv) Nascente com casas; v) Nascente com Policultivo.

Para a caracterização física das nascentes e do seu entorno foram observados e anotados os impactos ambientais positivos e negativos, descritos a seguir: presença de cerca, adoção de práticas conservacionistas, presença de serrapilheira, presença de fragmentos de mata ciliar, constatação de focos de erosão, confirmação quanto à aplicação de defensivos, acesso de animais domésticos no olho d'água, utilização da água para irrigação, presença de atividade agropecuária e trânsito de carros no entorno da nascente. As nascentes foram também classificadas quanto ao tipo de afloramento da água subterrânea em pontual ou difusa. Segundo Castro (2001), a nascente pontual ocorre em razão da inclinação da camada impermeável do solo ser menor que a do relevo, ocasionando o encontro delas em um determinado ponto do terreno, formando a nascente. Já, a nascente difusa é formada quando a camada impermeável do solo situa-se paralela à parte mais baixa e plana do terreno que, em razão da proximidade com a superfície, o fluxo d'água resulta em um aumento no nível do lençol freático, fazendo com que esse nível atinja a superfície do solo, ocasionando o surgimento de um grande número de pequenas nascentes por toda a área.

A coleta, acondicionamento e conservação das amostras de água, assim como as análises, foram realizados conforme metodologia recomendada pela Companhia de Saneamento de Minas Gerais (COPASA) tendo o acompanhamento do químico responsável pela unidade de Inconfidentes, MG. As amostras foram coletadas e avaliadas em quatro épocas do ano: (i) 23 de agosto de 2007; (ii) 14 de outubro de 2007; (iii) 6 de janeiro de 2008; e (iv) 24 de março de 2008, englobando, assim, os períodos seco e chuvoso do ano. As três primeiras amostragens (i, ii, e iii), foram analisadas na estação de tratamento de água do Município e aferidos os seguintes parâmetros: turbidez, cor, temperatura, $\mathrm{pH}$, coliformes totais e coliformes termotolerantes; constituindo as análise de rotina da água. A última amostragem (iv) foi analisada no Laboratório Regional Sul da COPASA, situado no Município de Varginha, MG e compreendeu as análises

Cerne, Lavras, v. 18, n. 3, p. 495-505, jul./set. 2012 
complementares: oxigênio dissolvido (OD), demanda bioquímica de oxigênio $\left(\mathrm{DBO}_{5}\right)$, fosfato total e nitratos, estes últimos objetivando a investigação de fertilizantes.

Os resultados das análises foram comparados com o padrão de potabilidade referenciado na portaria 518/04 do Ministério da Saúde (BRASIL, 2004).

Foi calculado o índice de qualidade da água (IQA) seguindo a metodologia padronizada pela Companhia de Tecnologia de Saneamento Ambiental do Estado de São Paulo - CETESB (2001), sendo atribuídos pesos conforme sua importância relativa para os parâmetros: (1) temperatura da amostra; (2) $\mathrm{pH}$; (3) oxigênio dissolvido; (4) demanda bioquímica de oxigênio (cinco dias, $20^{\circ} \mathrm{C}$ ); (5) coliformes termotolerantes; (6) nitrato; (7) fosfato total; (8) sólidos totais; e (9) turbidez, conforme Tabela 1.

Tabela 1 - Peso das características utilizadas no cálculo do índice de qualidade da água.

Table 1 - Weight of the characteristics used in the measurement of water quality index.

\begin{tabular}{lc}
\hline \multicolumn{1}{c}{ Características } & Pesos Relativos \\
\hline 1. Oxigênio Dissolvido & 0,17 \\
2. Coliformes termotolerantes & 0,15 \\
3. pH & 0,12 \\
4. Demanda Bioquímica de Oxigênio & 0,10 \\
5. Fosfato Total & 0,10 \\
6. Temperatura & 0,10 \\
7. Nitratos & 0,10 \\
8. Turbidez & 0,08 \\
9. Sólidos Totais & 0,08
\end{tabular}

Fonte: CETESB (2001)

O IQA das nascentes foi calculado pelo produto ponderado das notas atribuídas a cada característica de qualidade de água conforme equação 1 :

$$
I Q A=\prod_{i=1}^{n} q_{i}^{w i}
$$

onde:

$I Q A$ - índice de qualidade da água varia de 0 a 100;

$q_{i}$ : qualidade do i-ésimo parâmetro, um número entre 0 e 100, obtido da respectiva "curva média de variação de qualidade", em função de sua concentração ou medida; wi : peso correspondente ao i-ésimo parâmetro, um número entre 0 e 1, atribuído em função da sua importância para a conformação global de qualidade, conforme equação 2 :

$$
\sum_{i=n}^{n} W_{i}=1
$$

onde:

$n=$ número de parâmetros que entram no cálculo do IQA.

Os valores do IQA obtidos para as nascentes, foram comparados com os valores de referência para determinar a qualidade das águas, conforme classificação da Tabela 2 .

Tabela 2 - Faixas de variação de qualidade das águas (CETESB, 2001).

Table 2 - Range of variation of water quality (CETESB, 2001).

\begin{tabular}{lc}
\hline Variação & Faixa \\
\hline Qualidade Ótima & $79<\mathrm{IQA} \leq 100$ \\
Qualidade Boa & $51<\mathrm{IQA} \leq 79$ \\
Qualidade Regular & $36<\mathrm{IQA} \leq 51$ \\
Qualidade Ruim & $19<\mathrm{IQA} \leq 36$ \\
Qualidade Péssima & $\mathrm{IQA}<19$ \\
\hline
\end{tabular}

\section{RESULTADOS E DISCUSSÃO}

\subsection{Caracterização física das nascentes e do seu entorno}

O levantamento da caracterização física das nascentes e do seu entorno, baseados na observação e inspeção in situ, encontra-se na Tabela 3.

A nascente perturbada apresenta área de vegetação ciliar em área menor à prevista na Lei $\mathrm{n}^{\circ} 4.771 / 65$ (BRASIL, 1965), é pontual, possui mata estacional semidecidual secundária, com predominância de subbosque. O estado de conservação pode ser considerado bom, uma vez que apresenta mata nativa em 80 metros acima, 20 metros abaixo, 17 metros à direita e 14 metros à esquerda do olho d'água. Apresenta ainda grande quantidade de serrapilheira que pode constituir um excelente banco de sementes para o solo e propiciar a regeneração natural das espécies. Observando a Tabela 3 , verificou-se que esta nascente apresenta os impactos considerados positivos para o favorecimento da qualidade da água e da biodiversidade, tais como: presença de cercas, de serrapilheira e, consequentemente, banco de sementes e a adoção de práticas conservacionistas.

A nascente com pastagem é difusa, apresenta grau de degradação elevado, pois não há vegetação ciliar, mas apenas um indivíduo arbóreo (Ficus insipida) localizado a 15 metros acima do olho d'água. À direita da nascente

Cerne, Lavras, v. 18, n. 3, p. 495-505, jul./set. 2012 
Tabela 3 - Presença (P) ou ausência (A) de impactos ambientais positivos e negativos nas cinco nascentes de Inconfidentes - MG, (2008).

Table 3 - Presence $(P)$ or absence (A) of positive and negative environmental impacts in five water spring located in Inconfidentes, Minas Gerais State, Brazil, (2008).

\begin{tabular}{|c|c|c|c|c|c|c|c|}
\hline & & \multirow{2}{*}{ Parâmetros } & \multicolumn{5}{|c|}{ Nascentes } \\
\hline & & & perturbada & com pastagem & com café & com casas & com policultivo \\
\hline \multirow{12}{*}{$\begin{array}{l}\text { ô } \\
\text { : } \\
\tilde{\Xi} \\
\text { : }\end{array}$} & & Cerca & $\mathrm{P}$ & A & $\mathrm{P}$ & $\mathrm{P}$ & A \\
\hline & Positivos & Serrapilheira & $\mathrm{P}$ & A & A & A & A \\
\hline & Positivos & Mata ciliar parcial na APP & $\mathrm{P}$ & A & $\mathrm{P}$ & A & A \\
\hline & & Praticas conservacionistas & $\mathrm{P}$ & A & A & A & A \\
\hline & \multirow{8}{*}{ Negativos } & Erosão & A & $\mathrm{P}$ & $\mathrm{P}$ & A & $\mathrm{P}$ \\
\hline & & Atividade agrícola no entorno da nascente & A & A & $\mathrm{P}$ & $\mathrm{P}$ & $\mathrm{P}$ \\
\hline & & Defensivos aplicados no entorno da nascente & A & A & $\mathrm{P}$ & A & $\mathrm{P}$ \\
\hline & & Consumo para irrigação & A & A & A & $\mathrm{P}$ & $\mathrm{P}$ \\
\hline & & Uso de defensivos agrícolas & A & A & $\mathrm{P}$ & $\mathrm{P}$ & $\mathrm{P}$ \\
\hline & & Atividade pecuária no entorno da nascente & $\mathrm{P}$ & $\mathrm{P}$ & $\mathrm{P}$ & $\mathrm{P}$ & A \\
\hline & & Acesso de animais domésticos ao olho d'água & A & $\mathrm{P}$ & $\mathrm{P}$ & $\mathrm{P}$ & A \\
\hline & & Trânsito de carros no entorno da nascente & A & A & A & $\mathrm{P}$ & A \\
\hline
\end{tabular}

há predominância de gramínea nativa rasteira (Euphorbia heterophylla - amendoim bravo; Parapiptadenia rigida frango assado) em apenas 10 metros e, 5 metros à esquerda, há presença de Tipha domingensis (taboa), vegetação presente em nascentes difusas cuja bacia de contribuição está degradada e onde o assoreamento da nascente favoreceu o desenvolvimento dessa planta aquática. Dentre as nascentes estudadas, esta foi a que revelou maior número de impactos negativos (Tabela 3), explicando o estágio avançado de erosão que a área da nascente apresenta. A pastagem ocupa toda a área de recarga dessa nascente, comprometendo a regeneração natural em função do superpisoteio do gado e dos jumentos. Somase a esse fato, a competição por luz e nutrientes que as espécies em regeneração apresentam com as gramíneas forrageiras. Segundo Pinto (2003), as nascentes cujo entorno é composto por pastos com presença de animas ficam submetidas a prejuízos nos processos sucessionais de regeneração, em razão da quebra de plântulas pelo pisoteio e pastoreio, com prejuízos da regeneração natural. Conforme destacou Dean (1996), a presença de bovinos em nascentes favorece a compactação do solo e a disseminação de sementes de espécies invasoras que comprometem a regeneração natural de espécies arbóreas nativas, tornado-se um grande impedimento ao processo de conservação e preservação das matas remanescentes. Pode-se inferir que a compactação e a desestruturação do solo no entorno da nascente com pastagem tenham sido os fatores responsáveis pelo soterramento dessa nascente.

A nascente com cultivo de café é pontual, apresenta vegetação em estágio de sucessão inicial com algumas espécies arbóreas até 25 metros acima do olho d'água. Abaixo do olho d'água consta área de pastagem com presença de gado, possível fonte de contaminação da água para as casas que se beneficiam da água dessa mina; à esquerda, a 15 metros da nascente, existem plantas de bambu e à direita ocorre mata em regeneração que se estende por 10 metros, ressaltando que não há presença de serrapilheira (Tabela 3). Embora no entorno existam cerca e mata ciliar em área reduzida, os impactos negativos da pecuária e da agricultura podem ser responsabilizados pela erosão e a aplicação de defensivos, comprometendo o uso múltiplo das águas para a comunidade no entorno (DAVIDE; BOTELHO, 1999; NEMETH-KONDA et al., 2002). Além destes, Coletti et al. (2009), estudando o Rio da Pedras, em Mogi Guaçu/SP, demonstraram deterioração do IQA em função da atividade agrícola no entorno.

A nascente com casas é pontual e está canalizada. Apresenta-se totalmente desprovida de mata ciliar e a um

Cerne, Lavras, v. 18, n. 3, p. 495-505, jul./set. 2012 
metro acima do olho d'água há uma estrada com trânsito contínuo de carros, animais e pessoas. Abaixo, à direita e à esquerda do olho d'água existem treze domicílios que são abastecidos com água desta. A única proteção no entorno são paredes de concreto com altura de 1,5 metros ao redor da caixa de 10.000 litros. Essa nascente tem como impactos positivos a presença de cerca, ausência de erosão e de defensivos agrícolas e, como impactos negativos, a ausência de mata ciliar, presença das residências ao seu entorno, trânsito de carros acima da nascente e a presença de animais em pastagem adjacente (Tabela 3). Blume et al. (2010), descrevendo sobre o IQA do Rio Sinos associaram a redução da qualidade da água à poluição por esgoto doméstico, enquanto Pinto (2003) descreveu sobre a importância de remanescente de vegetação ciliar para obstrução de impurezas que venham a poluir o olho d'água, fato este que compromete sua qualidade.

A nascente com policultivo é pontual, tem predominância de Tipha domingensis (taboa) e capimgordura em um raio de aproximadamente 3 metros e a partir desse ponto existem várias culturas como de: uva, figo-da-índia, ponkã, laranja, banana e hortaliças. A maioria dos impactos negativos (Tabela 3) está presente nessa nascente, dentre eles destacam-se a ausência de cercas, ausência de mata ciliar no seu entorno e o emprego de defensivos agrícolas na produção de frutas e hortaliças sem adoção de práticas conservacionistas do solo. Bertoni et al. (1986) descreveram que a baixa utilização das práticas conservacionistas no preparo do solo tem contribuído com o processo de erosão, ocasionando o assoreamento, além desse fato, o emprego de defensivos agrícolas pode favorecer a contaminação das nascentes, fato que causa grande preocupação. Conforme salientou Guilherme et al. (2000), a maioria dos defensivos agrícolas, por exemplo, alguns herbicidas e inseticidas têm como destino final o solo e após serem depositados na superfície do solo, os pesticidas podem ser transportados juntamente com a água da enxurrada, contaminando rios, lagos e minas de água. Outra forma de contaminação ocorre quando os pesticidas são transportados juntamente com a água que infiltra verticalmente no solo, processo conhecido como lixiviação. Quando os pesticidas são lixiviados podem contaminar fontes de água subterrâneas, já que a água que infiltra no solo tem como uma de suas finalidades abastecer as reservas subterrâneas (SOPPER, 1975). Pode-se ainda inferir que a precipitação pluviométrica ocasione, nessa nascente, defluxo carreando solo que contém defensivo pulverizado nas culturas e que essa enxurrada seja direcionada por gravidade à nascente de onde a água é utilizada para o abastecimento domiciliar, incluindo dessedentação humana (Tabela 3). Além do risco à saúde humana e animal pelo contato direto com tais substâncias, existe o risco de contaminação ambiental. Trata-se de substâncias persistentes que permanecem durante muito tempo em solos, águas, vegetais e animais, portanto passíveis de serem consumidos. Almeida (1982) advertiu que envenenamentos agudos por pesticidas podem ocorrer na manipulação e aplicação dos mesmos, enquanto as lesões crônicas decorrem da ingestão por períodos prolongados de venenos persistentes no solo e água e/ou nos alimentos ingeridos, pois mesmo quando em reduzida quantidade se acumulam em tecidos e órgãos do organismo.

\subsection{Caracterização da água das nascentes}

3.2.1 Qualidade da água das nascentes: Análises de rotina

Os resultados das avaliações de caracteres físicos, químicos e biológicos que constituíram as análises de rotina, nos três períodos de amostragem (i, ii e iii), encontram-se na Tabela 4.

A nascente perturbada obteve a maioria dos resultados dentro dos padrões de potabilidade descritos na Portaria MS 518/04 (BRASIL, 2004). Esses padrões referem-se as seguintes características: temperatura, $\mathrm{pH}$, turbidez e a cor. A temperatura da água da nascente perturbada foi inferior em relação a das outras nascentes, corroborando os achados de Arcova, Cicco e Honda (2003) que concluíram que a ausência de matas ciliares nas nascentes proporciona o maior aquecimento das águas. A variação da temperatura nos vários períodos de amostragem foi de 19,0 a $20,0{ }^{\circ} \mathrm{C}$, refletindo condições semelhantes de sombreamento dos cursos de água proporcionados pela cobertura vegetal, resultando qualidade de água favorável à macro e micro fauna. Sperling (1995) descreveu que a maioria das espécies animais e vegetais tem exigências definidas quanto às temperaturas máximas e mínimas toleradas. Como as variações de temperatura da água compreendem parte do regime climático natural, elas exercem influência sobre o metabolismo de comunidades aquáticas, a produtividade primária, a respiração dos organismos e a decomposição da matéria orgânica. A explicação para a presença de coliformes totais e termotolerantes na segunda análise pode ser explicada pela entrada de um bovino na nascente perturbada, que saltou a cerca e permaneceu durante um mês na mata adjacente.

Cerne, Lavras, v. 18, n. 3, p. 495-505, jul./set. 2012 
Tabela 4 - Características físicas, químicas e biológicas da água nas cinco nascentes de Inconfidentes - MG, (2008).

Table 4 - Physico-chemical and biological characteristic in five water spring located in Inconfidentes, Minas Gerais State, Brazil, (2008).

\begin{tabular}{|c|c|c|c|c|c|c|c|c|}
\hline \multirow{2}{*}{ Características } & \multirow{2}{*}{ Unidade } & \multirow{2}{*}{$\mathrm{VMP}^{(1)}$} & \multirow{2}{*}{ Avaliações } & \multicolumn{5}{|c|}{ Nascentes } \\
\hline & & & & perturbada & com pastagem & com café & com casas & com policultivo \\
\hline \multirow{3}{*}{ Temperatura } & \multirow{3}{*}{${ }^{\circ} \mathrm{C}$} & \multirow{3}{*}{ - } & 1 & $20^{\circ}$ & $24^{\circ}$ & $22^{\circ}$ & $24^{\circ}$ & $23^{\circ}$ \\
\hline & & & 2 & $19^{\circ}$ & $22^{\circ}$ & $22^{\circ}$ & $23^{\circ}$ & $21^{\circ}$ \\
\hline & & & 3 & $19^{\circ}$ & $23^{\circ}$ & $20^{\circ}$ & $22^{\circ}$ & $21^{\circ}$ \\
\hline \multirow{3}{*}{$\mathrm{pH}$} & \multirow{3}{*}{$\mathrm{Mg} / \mathrm{L}$} & \multirow{3}{*}{6 à 9} & 1 & 7,4 & 6,9 & 6,2 & 5,9 & 6,4 \\
\hline & & & 2 & 6,6 & 6,8 & 6,1 & 5,5 & 6,2 \\
\hline & & & 3 & 6,7 & 6,7 & 6,0 & 5,7 & 5,9 \\
\hline \multirow{3}{*}{ Turbidez } & \multirow{3}{*}{$\mathrm{UT}^{(2)}$} & \multirow{3}{*}{5} & 1 & 0,11 & 31,00 & 13,00 & 1,20 & 2,94 \\
\hline & & & 2 & 0,55 & 52,00 & 0,98 & 0,50 & 0,93 \\
\hline & & & 3 & 0,20 & 25,00 & 20,00 & 0,80 & 0,80 \\
\hline \multirow{3}{*}{ Cor } & \multirow{3}{*}{$\mathrm{uH}^{(3)}$} & \multirow{3}{*}{15} & 1 & 5 & 150 & 45 & 5 & 15 \\
\hline & & & 2 & 3 & 240 & 5 & 3 & 5 \\
\hline & & & 3 & 3 & 130 & 60 & 3 & 5 \\
\hline \multirow{3}{*}{ Coliformes totais $/ 100 \mathrm{ml}$} & \multirow{3}{*}{$100 \mathrm{ml}$} & \multirow{3}{*}{$\begin{array}{l}\text { Ausência } \\
\text { em } 100 \mathrm{ml}\end{array}$} & 1 & 00 & $>2419$ & 199 & 63 & 38 \\
\hline & & & 2 & $\mathrm{P}$ & $\mathrm{P}$ & $\mathrm{P}$ & $\mathrm{P}$ & $\mathrm{P}$ \\
\hline & & & 3 & $\mathrm{~A}$ & $\mathrm{P}$ & $\mathrm{P}$ & $\mathrm{P}$ & $\mathrm{P}$ \\
\hline \multirow{3}{*}{$\begin{array}{l}\text { Coliformes } \\
\text { termotolerantes } / 100 \mathrm{ml}\end{array}$} & \multirow{3}{*}{$100 \mathrm{ml}$} & \multirow{3}{*}{$\begin{array}{l}\text { Ausência } \\
\text { em } 100 \mathrm{ml}\end{array}$} & 1 & 00 & 365 & 00 & 24 & 0 \\
\hline & & & 2 & $\mathrm{P}$ & $\mathrm{P}$ & $\mathrm{P}$ & $\mathrm{P}$ & $\mathrm{P}$ \\
\hline & & & 3 & A & $\mathrm{P}$ & $\mathrm{P}$ & $\mathrm{P}$ & $\mathrm{P}$ \\
\hline
\end{tabular}

Notas: ${ }^{(1)} \mathrm{VMP}=$ valor máximo permitido; ${ }^{(2)} \mathrm{UT}=$ Unidade de Turbidez; ${ }^{(3)} \mathrm{uH}=$ Unidade Hazen $(\mathrm{mg} \mathrm{Pt}-\mathrm{Co} / \mathrm{L})$.

$\mathrm{P}=$ presença; $\mathrm{A}=$ ausência.

A nascente com pastagem apresentou alterações com relação às características físicas cor e turbidez e às características biológicas coliformes totais e termotolerantes, que se revelaram acima do nível aceitável. Esses valores elevados de cor e turbidez (Tabela 4) podem ter ocorrido em razão da presença de erosão como consequência da compactação e da desestruturação do solo ocasionada pelo manejo indevido da pastagem e ainda, provavelmente, pelos animais que bebem água nessa nascente, fato evidenciado no estudo de Guerra, Silva e Botelho (1999). O solo erodido carreado para a nascente faz alterar a coloração e a turbidez da água que corrobora os achados de Arcova, Cicco e Honda (2003) e Pinto (2003). Em relação ao padrão microbiológico, os valores foram acima dos estabelecidos pela resolução CONAMA 357/2005 (BRASIL, 2005) para águas doces de classe 2, o que representa risco à saúde da população no entorno, a qual faz uso desta para sua dessedentação. A temperatura apresentou-se mais elevada em relação à nascente com maior raio de vegetação, provavelmente esse aumento se deva à ausência de vegetação ciliar. Segundo Arcova, Cicco e Honda (2003) e Sperling (1995), a manutenção da vegetação ciliar é a maneira mais efetiva de prevenir aumento da temperatura da água. Já, a característica pH, apresentou-se em conformidade com padrões estabelecidos na Resolução CONAMA 357/2005 (BRASIL, 2005).

A nascente com café apresentou as características físicas cor e turbidez acima do nível aceitável. Arcova e Cicco (1999) e Arcova, Cicco e Honda (2003), estudando a qualidade da água de microbacias com diferentes usos do solo na região de Cunha, verificaram que os valores de temperatura, turbidez e cor aparente da água em áreas de recarga com agricultura tiveram valores superiores aos registrados em áreas de recarga florestadas, o que também foi observado neste estudo. Além disso, a quantidade de coliformes totais encontrada foi 199 vezes acima do nível aceitável, também representando risco a saúde da população servida pela água dessa nascente.

Cerne, Lavras, v. 18, n. 3, p. 495-505, jul./set. 2012 
A nascente com casas apresentou as características físicas cor e turbidez dentro dos níveis preconizados, provavelmente em decorrência da caixa de 10.000 litros que está sobre a nascente e reserva toda água encanada direto da nascente. Em contrapartida, as contagens de coliformes totais e termotolerantes estiveram altas, provavelmente em razão da ausência de fossas sépticas nas casas. O efluente das fossas negras é lançado diretamente no rio, próximo a nascente. A natureza do efluente dessas fossas é representada por matéria orgânica vegetal, animal e humana (contaminantes), exigindo tratamento para serem reutilizadas, ainda que suas características físicas e químicas apresentem-se satisfatórias. Segundo descreveu Heller (1997), as águas superficiais, que são as mais utilizadas para o abastecimento de populações, são também as mais passiveis de contaminação por arrastarem substâncias resultantes da lavagem do solo em enxurradas, pela falta da mata ciliar (DAVIDE et al., 2004). Outros problemas de contaminação das águas superficiais estão relacionados aos resíduos sólidos e incluem: poluição dos mananciais pelo chorume; assoreamento (depósito do lixo em leitos de rios e córregos), conforme estudo de Barroso e Silva (1992). Um sério problema para a saúde de comunidades na zona rural está relacionado aos dejetos domésticos, principalmente fezes e urina por conterem grande número de agentes patogênicos, os quais na falta de sistemas de esgotos sanitários permanecem no meio ambiente, podendo constituir fontes de transmissão de doenças. Esse fato está relacionado com a ocupação de $70 \%$ dos leitos hospitalares em função da ingestão de água contaminada, propagando doenças como a cólera, hepatite, diarréia, salmonelose, além de outras (CLARKE; KING, 2005).

A nascente com policultivo obteve as características biológicas fora do padrão recomendado pela Portaria $n^{\circ} 518 / 2004$ do Ministério da Saúde (BRASIL, 2004), em todas as avaliações, porém as características físicoquímicas se mantiveram dentro dos níveis recomendados. De forma educativa, foi alertado, na primeira inspeção, que algumas características de qualidade da água estavam comprometidas e esse dado causou grande preocupação coletiva, pois ocorre o consumo da mesma por pessoas e animais, além do uso para irrigação de alimentos vendidos na comunidade. Nas demais avaliações, os valores das características cor e turbidez apresentaram-se superiores aos da primeira avaliação, pois houve mudança de atitude do proprietário após a divulgação dos resultados da primeira análise que passou a preservar e a desenvolver boas práticas de proteção e conservação de sua nascente como: minimizar os processos de erosão por meio de barreiras vegetais de contenção e instalação de cercas na área que margeia a mina, fato este que possibilitou a regeneração natural da mata. Segundo Arcova, Cicco e Honda (2003) e Sopper (1975), as nascentes com vegetação promovem a proteção contra a erosão do solo, a sedimentação e a lixiviação excessiva de nutrientes.

3.2.2 Qualidade de água das nascentes: Análises complementares

As características químicas complementares avaliadas para comparar a qualidade da água das nascentes encontram-se na Tabela 5.

Tabela 5 - Características químicas complementares da qualidade da água nas cinco nascentes de Inconfidentes - MG, (2008).

Table 5 - Additional chemical characteristic of water quality in five water spring located in Inconfidentes, Minas Gerais State, Brazil, (2008).

\begin{tabular}{|c|c|c|c|c|c|c|c|}
\hline \multirow{2}{*}{ Características } & \multirow{2}{*}{ Unidade } & \multirow{2}{*}{$\mathrm{VMP}^{(1)}$} & \multicolumn{5}{|c|}{ Nascentes } \\
\hline & & & perturbada & com pastagem & com café & com casas & com policultivo \\
\hline Temperatura ambiente & ${ }^{\circ} \mathrm{C}$ & - & 26 & 25 & 25 & 26 & 26 \\
\hline Temperatura amostra & ${ }^{\circ} \mathrm{C}$ & - & 19 & 21 & 21 & 23 & 20 \\
\hline Sólidos totais & $\mathrm{mg} / \mathrm{L}$ & - & 0 & 748 & 94 & 68 & 24 \\
\hline $\mathrm{DBO}^{(2)}$ & $\mathrm{mg} / \mathrm{L}$ & 5,0 & $<0,5$ & 2,8 & $<0,5$ & 1,9 & 2,2 \\
\hline Fosfato total & $\mathrm{mg} / \mathrm{L}$ & 0,10 & 0,10 & 0,13 & 0,16 & $<0,02$ & $<0,02$ \\
\hline Nitratos & $\mathrm{mg} / \mathrm{L}$ & 10,00 & 3,71 & 1,38 & 1,21 & 11,10 & 9,89 \\
\hline $\mathrm{OD}^{(3)}$ & $\mathrm{mg} / \mathrm{L}$ & $\geq 6,0$ & 6,1 & 7,6 & 3,8 & 5,8 & 7,9 \\
\hline
\end{tabular}

Notas: (1) VMP = valor máximo permitido pela Resolução 357/05 - CONAMA (BRASIL, 2005); (2) DBO = Demanda Bioquímica de Oxigênio; ${ }^{(3)} \mathrm{OD}=$ Oxigênio Dissolvido.

Cerne, Lavras, v. 18, n. 3, p. 495-505, jul./set. 2012 
A nascente perturbada obteve as características fosfato total, nitratos, $\mathrm{OD}$ e $\mathrm{DBO}_{5}$ dentro dos valores máximos permitidos pela Resolução 357/05-CONAMA (BRASIL, 2005). Valor de $\mathrm{DBO}_{5}$ aceitável retrata que a quantidade das necessidades respiratórias da população microbiológica para a decomposição da matéria orgânica presente foi suficiente. A característica nitrato com valor dentro do máximo permitido confirma o estudo de Sopper (1975), que mostrou que áreas de recarga com vegetação promovem a proteção contra a sedimentação e a lixiviação excessiva de nutrientes, sendo essas áreas muito importantes para manter o abastecimento de água de boa qualidade. Com a caracterização física das nascentes verificou-se que essa nascente foi a que apresentou o maior raio de cobertura florestal.

Na nascente com pastagem, somente a característica fosfato total encontrou-se fora dos padrões da Resolução 357/05- CONAMA (BRASIL, 2005). O maior valor do fosfato total pode ser explicado pela presença do elemento químico em fezes e/ou rompimento de depósitos naturais consequentes da erosão de rochas que contenham fosfatos, agravados pela ausência da vegetação nessa nascente, conforme citaram Donadio, Galbiatti e Paula (2005) e Sperling (1996).

A nascente com café apresentou as características fosfato total e OD fora dos níveis aceitáveis. A correlação entre essas características deve-se a processos eutróficos que podem ser observados nos dias de hoje (VALENTE; PADILHA; SILVA, 1997). Esses processos acontecem rapidamente em consequência das atividades humanas (MARQUES; BOAVIDA, 1997), podendo ter resultados negativos para populações aquáticas como a diminuição progressiva da concentração de oxigênio dissolvido na água. $\mathrm{O}$ valor de $\mathrm{OD}$ de 3,8 encontrado nessa nascente poderá, segundo Sperling (1995), ocasionar a morte de peixes mais sensíveis. A presença do fosfato total na água dessa nascente corrobora com estudos de Sperling (1996), que salienta que a classe de compostos organofosforados está presente nos defensivos mais utilizados na agricultura brasileira para o controle de diversos tipos de pragas.

Na nascente com casas, o fator de maior preocupação encontrado nos resultados das análises laboratoriais foi a presença do nitrato. Provavelmente, a explicação deve-se a ausência das fossas sépticas nas residências à montante dessa nascente. Os efluentes sanitários somados ao despejo de resíduos orgânicos de origem domiciliar, ricos em gorduras e detergentes podem ter percolado para o lençol freático, corroborando os achados de Silveira e Sant'Anna (1990). Marques e Boavida (1997) acrescentam o comprometimento da saúde humana e/ou impacto aos ecossistemas aquáticos, principalmente pela diminuição do oxigênio dissolvido na água, causado pelo excesso de nitrogênio.

A nascente com policultivo obteve todas as características dentro dos padrões da resolução 357 do CONAMA (BRASIL, 2005), porém um fato a ser destacado é a conscientização desse produtor que possibilitou a regeneração natural da mata, pois no início desse estudo a nascente apresentava ausência total de mata ciliar. Segundo Arcova, Cicco e Honda (2003), Davide et al. (2004), Donadio, Galbiatti e Paula (2005) e Pinto (2003), as nascentes com vegetação promovem a proteção contra a erosão do solo, a sedimentação e a lixiviação excessiva de nutrientes, sendo essas áreas muito importantes para manter o abastecimento de água de boa qualidade, corroborando com o presente estudo.

\subsection{3 Índice de qualidade da água (IQA)}

Com base nos valores obtidos para as características OD, coliformes termotolerantes, $\mathrm{pH}, \mathrm{DBO}_{5}$, fosfato total, temperatura, nitrato, turbidez e sólidos totais calculou-se o IQA das nascentes, representado na Figura 1. O IQA da nascente perturbada foi de 90,64, valor entre 79 e 100, o que significa uma Qualidade Ambiental Ótima. As demais nascentes apresentaram valores do IQA entre 51 e 79, o que significa uma Qualidade Ambiental Boa para as nascentes com pastagem $(58,07)$, com café $(58,75)$, com casas $(65,19)$ e com policultivo $(75,02)$.

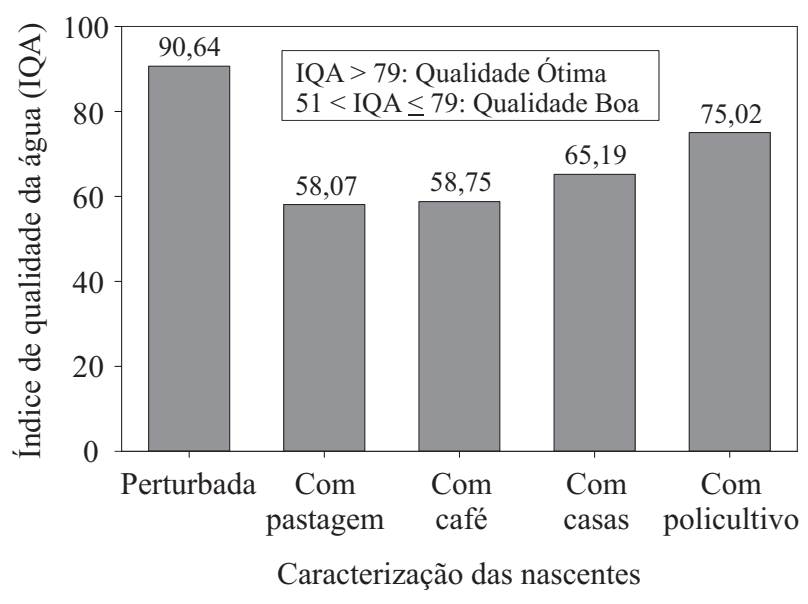

Figura 1 - Representação gráfica do índice de qualidade da água (IQA) das cinco nascentes de Inconfidentes - MG (2008).

Figure 1 - Water quality index (WQI) of five water springs located in Inconfidentes, Minas Gerais State, Brazil, 2008.

Cerne, Lavras, v. 18, n. 3, p. 495-505, jul./set. 2012 
Conforme Simões et al. (2007), a utilização de IQA é imprescindível para o monitoramento da qualidade dos recursos hídricos, em razão dos baixos custos, bem como sua importância para a tomada de decisão em recursos hídricos ainda pouco estudados. O IQA representa uma ferramenta de gestão ambiental imprescindível para os órgãos públicos, porém se faz necessária uma investigação mais detalhada que indique caso a caso qual o melhor indicador ambiental.

Deve-se destacar que embora as cinco nascentes estejam enquadradas dentro de categorias aceitáveis do indicador IQA, este não se adequa à qualidade da água para consumo humano na nascente com pastagem no entorno que apresentou padrões de coliformes termotolerantes acima do recomendado na portaria 518/MS (BRASIL, 2004) e a despeito desse achado, foi classificado na categoria de IQA Boa, com valor 58,07.

\section{CONCLUSÕES}

A presença de vegetação ciliar na nascente perturbada auxiliou na proteção quali-quantitativa de seus recursos hídricos, ao longo dos períodos de amostragem, em comparação às nascentes com pastagem, com café, com policultivo e com casas, sendo as características cor, turbidez, coliformes totais e termotolerantes, $\mathrm{DBO}_{5}$, fosfato total, nitrato e OD as que mais evidenciaram essas diferenças.

A nascente com pastagem foi a que se apresentou mais degradada em decorrência do avançado estágio de erosão causando significativa alteração da cor e turbidez.

$\mathrm{Na}$ nascente com café, a presença de atividade agropecuária com emprego de defensivos agrícola afetaram os níveis de oxigênio dissolvido e de fosfato total na água.

$\mathrm{Na}$ nascente com casas, os fatores de comprometimento da qualidade da água foram a ausência de mata ciliar e a presença de residências com fossas negras ao seu entorno, fator que pode ser responsabilizado pelo excesso de nitrogênio presente nesse reservatório.

A nascente com policultivo apresentou a maioria dos impactos negativos, porém sem comprometimento da qualidade da água.

As cinco nascentes se enquadraram nas categorias ótima e boa do IQA.

\section{AGRADECIMENTOS}

À Empresa de Saneamento de Minas Gerais (COPASA) pela realização das análises.

\section{REFERÊNCIAS}

ALMEIDA, W. F. de. Toxidade dos pesticidas, seu controle e restrição de venda. In: GRAZIARO NETO, F. (Coord.). Uso de agrotóxico e receituário agronômico. São Paulo: Agroedições, 1982. p. 59-73.

ARCOVA, F. C. S.; CICCO, V. Características do deflúvio de duas microbacias hidrográficas no laboratório de hidrologia florestal Walter Emmench, Cunha, SP. Revista do Instituto Florestal de São Paulo, São Paulo, v. 9, n. 2, p. 153-170, 1997.

ARCOVA, F. C. S.; CICCO, V. Qualidade da água de microbacias com diferentes usos do solo na região de Cunha, Estado de São Paulo. Scientia Forestalis, Piracicaba, v. 5, n. 6, p. 125-134, 1999.

ARCOVA, F. C. S.; CICCO, V.; HONDA, E. A. Pesquisas sobre qualidade da água em Bacias Hidrográficas do Alto Paraíba do Sul. In: WORKSHOP EM MANEJO DE BACIAS HIDROGRÁFICAS, 7., 2003, Cunha. Anais... Cunha, 2003. p. 101.

BARROSO, D. G.; SILVA, M. L. V. Poluição e conservação dos recursos naturais solo e água. Informe Agropecuário, Belo Horizonte, v. 16, n. 176, p. 17-24, 1992.

BERTONI, J.; PASTANA, F. I.; LOMBARDI NETO, F.; BENATTI JUNIOR, R. Conclusões gerais das pesquisas sobre conservação do solo no Instituto Agronômico. Campinas: Instituto Agronômico, 1986. 57 p. (Circular, 20).

BLUME, K. K.; MACEDO, J. C.; MENEGUZZI, A.; SILVA, L. B.; QUEVEDO, D. M.; RODRIGUES, M. A. S. Water quality assessment of the Sinos River, Southern Brazil. Brazilian Journal Biology, Rio de Janeiro, v. 70, n. 4, p. 1185-1193, 2010.

BRAGA, B.; HESPANHOL, I.; CONEJO, J. G. L.; BARROS, M. L.; SPENCER, M.; PORTO, M.; NUCCI, N.; JULIANO, N.; EIGER, S. Introdução à engenharia ambiental. São Paulo: Prentice Hall, 2002. 305 p.

BRASIL. Lei $\mathbf{n}^{\mathbf{0}}$ 4.771, de 15 de setembro de 1965. Institui o novo Código Florestal. Brasília, 1965. Disponível em: <http:// www.planalto.gov.br/CCIVIL/Leis/L4771.htm>. Acesso em: 7 abr. 2008.

Cerne, Lavras, v. 18, n. 3, p. 495-505, jul./set. 2012 
BRASIL. Lei $\mathbf{n}^{\mathbf{0}}$ 9.433, de 8 de janeiro de 1997. Institui a Política Nacional de Recursos Hídricos. Brasília, 1997. Disponível em: <http://www.planalto.gov.br/ccivil_03/LEIS/ L9433.htm>. Acesso em: 14 mar. 2008.

BRASIL. Ministério da Saúde. Secretaria de Vigilância em Saúde. Portaria n 518/2004 . Brasília, 2005. 28 p.

BRASIL. Ministério do Meio Ambiente. Resolução

CONAMA n ${ }^{\mathbf{0}}$ 303, de 20 de março de 2002. Brasília, 2002.

BRASIL. Ministério do Meio Ambiente. Resolução CONAMA n ${ }^{0}$ 357, de 17 de março de 2005. Brasília, 2005.

CASTRO, P. S. Recuperação e conservação de nascentes. Brasília: CPT, 2001. 84 p. (Série Saneamento e Meio Ambiente, Manual, 26).

CLARKE, R.; KING, J. O atlas da água. São Paulo: Publifolha, 2005. 128 p.

COLETTI, C.; TESTEZLAF, R.; RIBEIRO, T. A. P.; SOUZA, R. T. G.; PEREIRA, D. A. Water quality index using multivariate factorial analysis. Revista Brasileira de Engenharia Agrícola Ambiental, Campina Grande, v. 14, n. 5, p. 517-522, 2010.

\section{COMPANHIA DE TECNOLOGIA DE SANEAMENTO} AMBIENTAL DO ESTADO DE SÃO PAULO. Relatório de qualidade das águas interiores do estado de São Paulo. São Paulo, 2001. v. 1, 214 p.

DAVIDE, A. C.; BOTELHO, S. A. Análise crítica dos programas de recomposição de matas ciliares, em Minas Gerais. In: SIMPÓSIO MATA CILIAR CIÊNCIA E TECNOLOGIA, 1999, Belo Horizonte. Anais... Lavras: UFLA/FAEPE/CEMIG, 1999. p. 172-188.

DAVIDE, A. C.; PINTO, L. V. A.; MONNERAT, P. F.; BOTELHO, S. A.; PRADO, N. J. S. Nascente: o verdadeiro tesouro da propriedade rural. 2. ed. Belo Horizonte: CEMIG, 2004. $62 \mathrm{p}$.

DEAN, W. A ferro e fogo. São Paulo: Schwarez, 1996. 484 p.

DONADIO, N. M. M.; GALBIATTI, J. A.; PAULA, R. C. Qualidade da água de nascentes com diferentes usos do solo na bacia hidrográfica do córrego rico, São Paulo, Brasil.

Cerne, Lavras, v. 18, n. 3, p. 495-505, jul./set. 2012
Engenharia Agrícola, Jaboticabal, v. 25, n. 1, p. 115-125, jan./abr. 2005.

GUERRA, A. J. T.; SILVA, A. S.; BOTELHO, R. G. M. Erosão e conservação de solos: conceitos temas e aplicações. Rio de Janeiro: Bertrand Brasil, 1999. 339 p.

GUILHERME, L. R. G.; SILVA, M. L. N.; LIMA, J. M.; RIGITANO, R. L. de O. Contaminação de microbacia hidrográfica pelo uso de pesticidas. Informe Agropecuário, Belo Horizonte, v. 21, n. 207, p. 40-54, 2000.

HELLER, L. Saneamento e saúde. Brasília: OPAS/OMS, 1997. $97 \mathrm{p}$.

MARQUES, R. T.; BOAVIDA, M. J. Monitoring water quality in the portuguese reservoirs of the River Tejo watershed. Verh International Vereinment Limnology, Uppsala, v. 26, p. 740-744, 1997.

NEMETH-KONDA, L.; FÜLEKY, G.; MOROVJAN, G.; CSOKAN, P. Sorption behaviour of acetochlor, atrazie, carbendazim, diazinon, imidacloprid and isoproturon on Hungarian agricultural soil. Chemosphere, Amsterdam, v. 44, p. $545-552,2002$.

OLIVEIRA-FILHO, A. T.; ALMEIDA, R. J. de; MELLO, J. M. de; GAVILANES, M. L. Estrutura fitossociológica e variáveis ambientais em um trecho de mata ciliar do córrego Vilas Boas, Reserva Biológica do Poço Bonito, Lavras, MG. Revista Brasileira de Botânica, São Paulo, v. 17, n. 1, p. 67-85, 1994.

PINTO, L. V. A. Caracterização física da bacia do ribeirão Santa Cruz, Lavras, MG, e propostas de recuperação de suas nascentes. 2003. 165 p. Dissertação (Mestrado em Engenharia Florestal) - Universidade Federal de Lavras, Lavras, 2003.

SILVEIRA, S. S. B.; SANT’ANNA, F. S. P. Poluição hídrica. In: MARGULIS, S. (Ed.). Meio ambiente: aspectos técnicos e econômicos. Brasília: IPEA/PNUD, 1990. p. 57-86.

SIMÕES, F. S. dos; YABE, M. J. S. dos; MOREIRA, A. B.; BISINOTI, M. C. Avaliação do efeito da piscicultura em sistemas aquáticos em Assis e Cândido Mota, São Paulo, por indicador de qualidade da água e análise estatística multivariada. Química Nova, São Paulo, v. 30, n. 8, p. 18351841, ago. 2007. 
SOPPER, W. E. Effects of timber harvesting and related management practices on water quality in forested watersheds. Journal of Environmental Quality, Madison, v. 4, p. 24-29, 1975.

SPERLING, M. von. Introdução à qualidade das águas e ao tratamento de esgotos. Belo Horizonte: UFMG/DESA, 1995. v. 1,246 p.
SPERLING, M. von. Princípios do tratamento biológico de águas residuárias. 2. ed. Belo Horizonte: UFMG, 1996. v. 2 , $243 \mathrm{p}$.

VALENTE, J. P. S.; PADILHA, P. M.; SILVA, A. M. M. Contribuição da cidade de Botucatu, SP com nutrientes (fósforo e nitrogênio) na eutrofização da represa de Barra Bonita. Eclética Química, Marília, v. 22, p. 31-48, 1997.

Cerne, Lavras, v. 18, n. 3, p. 495-505, jul./set. 2012 
